\title{
The rise of violence as a result of inefficiency in healthcare system
}

\author{
Prof. Carine MILCENT \\ Carine.milcent@psemail.eu \\ CNRS - PSE
}

In 2009, the Chinese government published a large scale development plan the the health sector, with over 770 billion RMB to be invested. Four years later, 620 billion RMB has already been spent, with public insurance scheme set-up and Community Health Centers created. Yet, the key issues of the Chinese health systems have remained, leading to a tense relation between doctors and patients, with increasingly common acts of violence.

Indeed, China is currently experiencing an over-utilization of university hospitals and hospitals with high-tech equipment, usually located in main cities, in spite of them having an important capacity. This true for admissions, with a rate of occupancy above $100 \%$, as much as for outpatient activity.

In parallel, there is under-utilization of smaller institutions that have an occupancy rate between

According to the Health Ministry ${ }^{1}$, level 3 hospitals represents $2 \%$ of the total number of hospitals but $37 \%$ of consultations. For instance, every day 700,000 patients are coming from other hospitals to be treated in Beijing. ${ }^{2}$

The Ministry estimates that $70 \%$ of patients treated in level III hospitals could have received adequate treatment in hospitals of lower category, closer to their home.

\section{Yinao or hospital violence}

Yi (medical) Nao (dispute/violence): different forms of violence have been developing over the years in Chinese hospitals. It can take quite passive form, such as exposing the body of a defunct in front of the hospitals to very active forms like vandalism or even direct physical altercations with hospital staff, up to involving organized gangs ${ }^{3}$. Key words "hospital / violence / China" on

\footnotetext{
${ }^{1} \mathrm{MoH}$, China Health Statistical Yearbook, 2012

2 Source: National Health and Family Planning Commission, figures estimated in 2013 http://europe.chinadaily.com.cn/opinion/2017-05/04/content_29194712.htm accessed September 2017

${ }^{3} \mathrm{Tu}$ J. «Yinao: Protest and Violence in China's Medical Sector», dec.2015, Berkeley Journal of Sociology. http://berkeleyjournal.org/2014/12/yinao-protest-and-violence-in-chinas-medical-sector/ accessed September 2017
} 
any search engine will deliver scores of press articles covering cases of physicians being assaulted and sometimes even killed by patients.

Each year, more than 10,000 physicians are said to be assaulted one way or another. The number of reported incidents was 17,243 in 2010, up 70\% from 2004. According from a 2012 report $^{4}$, the number of conflicts between medical personnel and patients and their family is increasing by $22.9 \%$ per annum. A survey covering 10 Chinese provinces shows that half of Chinese doctors have been at least once verbally assaulted and one third physically assaulted ${ }^{5}$. This is consistent with the conclusion of the 2012 national forum of Chinese hospital presidents 2012, estimating that about 30 percent of medical personnel have had conflicts with their patients. ${ }^{6}$

In February 2014, a doctor in Northeast China's Heilongjiang Province was beaten to death by a patient. In January 2015, in Zhengzhou, a doctor and a patient died following a fight in a central China hospital ${ }^{7}$. In July 2015, the China Daily was reporting that an online petition demanding some crackdown on violence against hospital personal had collected the signature of more than 600,000 doctors $^{8}$. This petition was started after the attack of a physician by a patient during his service at Longmen County People's Hospital, in Guangdong province. In May 2016, still in Guangdong province, the death of a retired doctor after being stabbed in a knife attack by a former patient was reported by the China Daily reported. ${ }^{9}$

Overall, Chinese national media have covered roughly thirty medical related violent disputes (including fatal stabbings) from October 2013 to June 2015. Besides, there were thousands of small disputes happening in hospitals across China every day not making it to national news media. $^{10}$

We have seen earlier in this book how the hierarchy of Chinese healthcare system progressively eroded and drove the demand to concentrate on certain hospitals. How did this impact the efficiency of the entire system and lead to a situation where some patients see violence as their only option? The key elements to answer this question are:

- The changes in healthcare supply

i) The shift in the way hospitals are financed and manage their staff

ii) Conditions of consultation and admission in Level III hospital, tainted by waiting list tickets sold on black market and bribes to cut through waiting lines ;

iii) The low social recognition of medical careers and overall lack of consideration for the medical staff ;

\footnotetext{
${ }^{4}$ Wang, Zhongming and Jianhua Li. 2012. "Yiliaojiufen fasheng de yuanyin ji yingduicuoshi" ("The reason and countering measures of medical disputes"). Zhongguo Shequ Yishi (Chinese Community Doctor). No. 12, 409-410.

5 "Every year ten thousands doctors were attacked, the fragile doctor-patient relationship could not stand the heavy burden of attacks, when could the violence stop?" ("Meinian yiwan yisheng bei ouda, cuiruo yihuan jinbuqi zhongya, baoli shang yisheng heshixiu")

'Cao, Kai. "Hospitals' Return to Public Service Key to Tackle Doctor-Patient Disputes.” Xinhua 19 Nov 2011. Web. 30 Sep. 2013.

${ }^{7}$ http://www.chinadailyasia.com/nation/2015-01/26/content_15219326.html accessed September 2017

8 «600,000 Chinese doctors sign petition against hospital violence », China daily, 19 July 2015.

http://www.chinadaily.com.cn/china/2015-07/19/content_21326495.htm

accessed September 2017

${ }^{9}$ http://www.chinadailyasia.com/nation/2016-05/07/content_15429118.html

accessed September 2017

${ }^{10}$ http://www.whatsonweibo.com/new-law-combats-chinas-yinao-phenomenon/

accessed September 2017
} 
iv) The lack of legal recourse in case of suspected medical malpractice ;

- The changes in healthcare demand

i) Spatial changes in healthcare demand including urbanization and occupational changes

ii) The easier dissemination of information with the development internet and the web platforms, improving the level of knowledge of patients and their relatives

\section{The origin of such violence}

\section{Changes in supply}

\section{Hospital financing and personnel management}

The uniqueness of the Chinese hospital system is that they abruptly shifted from offering care almost independently from any financial consideration to operating like for-profit entities, though investments choices and pricing policy, while still retaining the governance of a public institution (as for instance, the medical personnel with a bian₹bi status has safety of employment and other benefits, as described in Chapter 4). Additionally, hospitals are to a large extent in a monopoly situation on their local area, which creates a lack of regulation in price setting by the market. The hospital can increase its revenue by offering more costly care and has all incentives to do so.

Due to this necessity for public hospitals to finance themselves, they distribute all sorts of income supplement to doctors and medical staff, often in a non-transparent way, with the objective to boost the activity and revenue. It is useful to break down the sources of income for physicians into four categories:

- Basic salaries as hospital employees ;

- Productivity-based bonuses paid by the hospital ;

- Drug rebates, consisting of payments from drug companies and hospitals, related to the physician prescribing behavior ;

- Gifts from patients, known as « hongbao» or « red envelopes».

The last two sources of revenue are considered as bribery and totally forbidden but are still widespread practice. They have widely contributed to patient distrust.

The second source of revenue is an incentive for the medical staff to increase the profit of the public hospital with the multiplication of the number of visits, and to over-prescribe. This behavior creates what is called induced demand. The objective function of medical personnel and physicians then includes profit maximization as a parameter. A search for profit then becomes central to an activity whose remuneration was until then totally disconnected from it. As a case in point, we can quote the sales of medicine drugs that now account for more than $40 \%$ of the turnover of public hospitals, with some abuse. According to the World Health Organization, the situation is such that antibiotics are prescribed at twice the race recommended and antiinflammatory drugs at more than three times the rate found in similar countries. The victims of this situation are patients, for whom the cost of care dramatically increases, with a lot of unnecessary prescription. All of this contributes to an ever tenser relationship between medical personnel and patients. 
To study the doctor-patient relationship, a survey was carried out in Shenzhen in December 2013. The data containing 504 licensed medical doctors was drawn by random sampling. To explain the over-prescription behaviour, a critical predictor is the low basic salaries as hospital employees. However, this study shows that over-prescription is also driven by doctors' intention to avoid disputes with patients.

In a 2016 qualitative study, Tucker et al. ${ }^{11}$ proposed to better understand the determinants of the current patient-physician mistrust and violence in Guangdong province. This study is based on one hundred and sixty patients, their family members, physicians, nurses and hospital administrators in seven hospitals. According to the authors, "the blind pursuit of financial profits at a systems level has eroded patient-physician trust in China".

On the medical staff side, these additional sources of revenue are justified by the level of basic salaries as hospital employees, considered far too low (see Chapter 4). Medical staff prefers to remain in the public sector because of the advantage tied with their bianzbi status. At the same time, according to a 2011 Chinese Medical Association survey, only 20\% of responding doctors are satisfied with their medical practice environments.

\section{Consultation and admission conditions in level 3 hospitals with current congestion context}

The number of Community Health Centers (CHCs) have been skyrocketing over the last few years, making it possible to consult without long waiting lines. Yet, demand little adapted to this new organization of supply. These newly set-up structures remain under-used by patient who still prefer level 3 hospitals. For level 3 hospitals, occupancy rate is above $100 \%$, when it is only around $80 \%$ for District Hospitals and between $50 \%$ and $60 \%$ in $\mathrm{CHCs}^{12}$.

Level 3 hospitals continue to have their number outpatient consultations increase and all the more so for inpatient admissions. Between 2007 and 2011, the number of consultations soared by $33 \%$ and admissions by $56 \%$. It has been estimated that $30 \%$ of admissions are unnecessary 13 . For some analysts, this situation has been exacerbated by the official classification of public hospitals based on their level of equipment and training of physicians, as it has objectivized the preference of patients for these hospitals. Similarly, Shanghai's Fudan University has released a list of China mainland's top 100 hospitals. The goal was to encourage hospitals to do better. An external effect was to encourage patients to go to hospitals from this list, i.e. the already overcrowded elite institutions. According to the South China Morning Post, " the rankings garnered plenty of coverage in the media, leading micro-bloggers to say they would save the list and use it as a reference if they ever needed to go to hospital $\gg{ }^{14}$

\footnotetext{
${ }^{11}$ Tucker JD, Cheng Y, Wong B, et al. Patient-physician mistrust and violence against physicians in Guangdong Province, China: a qualitative study. BMJ Open. 2015;5(10)

12 Source : MoH, China National Health Yearbook 2009.

http://www.mckinsey.com/ /media/mckinsey/dotcom/client_service/healthcare $\% 20$ systems $\% 20$ and $\% 20$ services $/$ health $\% 20$ international/hi10_china_healthcare_reform.ashx accessed September 2017

${ }^{13}$ Urban China: Toward Efficient, Inclusive, and Sustainable Urbanization Par The World Bank;Development Research Center of the State Council, Source MoH, 2011.

14 http://www.scmp.com/news/china/article/1094805/fudan-universitys-top-hospitals-list-blamed-worsening-bedcrunch

accessed September 2017
} 
In summary, it is fair to say to public hospital represent almost all medical consultations and hospital admissions. Over the entire Chinese territory, they represent $89 \%$ of the total number of hospital beds, $91.6 \%$ of the admissions and $91.7 \%$ of outpatient consultations ${ }^{15,16}$. According to a study, $20 \%$ of outpatients are treated for colds or gastroenteritis (Lim, 2002) ${ }^{17}$.

As a result of this concentration of demand, the more public hospital have high level equipment and trained physicians, the more they are congested. On the website of the Beijing Hospital, it is said that 4,500 medical consultations are performed there every day. Depending on the sources, the number of consultations per physicians is between 60 and 80 per day.

In the end, conditions of consultations end up being quite prone to create tension:

- Physicians are overwhelmed by demand, having very little time for each patient (as little as 2 minutes in certain, not uncommon cases), both because of the long waiting lines and because they are financially incentivized on the number of consultations they perform.

- Physicians are also incentivized to over-diagnose and over-prescribe, while giving little explanation to patients, due to the lack of time, in a context of asymmetry of information where the patient cannot appreciate the relevance of the diagnosis and prescriptions.

\section{... with waiting lines tainted by a black market of waiting tickets and bribery to cut through}

\section{lines}

One of the consequences of current situation of congestion is the development and trivialization of a black market to deal waiting tickets. Indeed, as a first step, patients usually wait in line to take a number just to be allowed to make an appointment. Scalpers can run a thriving practice trading numbers outside hospitals. Even if the ticket itself is not for free, its cost is too low to prevent this traffic, in particular for level 3 hospitals. As a case in point, in one of the best equipped hospital in Beijing, the Peking University Renmin Hospital, each waiting tickets costs 5 RMB, with the total tickets distributed per day being a closed number. On the black market, their price can rapidly grow to $200 \mathrm{RMB}$ and sometimes even higher, increasing the total cost of consultation.

\section{The difficulty of referring towards the right specialist}

The visit of public hospitals is quite instructive on the management of outpatients. Hospital are divided in two sectors. The sector dedicated to outpatients usually starts with a huge entry hall with a reception desk in the middle, attended by nurses. The role is to direct patients toward the specialty they need. Yet, this desk is usually well understaffed, making it difficult to address all the requests for information from patients.

A researched from CASS explains:

\footnotetext{
15 Source: Chinese Health Statistical Yearbook (2012).

${ }^{16}$ Barber S., Borowitz M., Bekedam H et Ma J. (2014) «The hospital of the future in China: China's reform of public hospitals and trends from industrialized countries » Health Policy and Planning, 29(3):367-78

${ }^{17}$ Lim M., Yang T., Zhang Z., Zhao F., Feng, W., Chen, Y. (2002) «The role and scope of Private Medical Practice in China » Final report to the world Health Organization and the United Nations Development Program, UNDP, WHO and MOH China.
} 
"The number of nurses at the reception desk doesn't make it possible to treat all the requests. As a result, the patient himself must often chose the specialty to consult. He must take a waiting number and is then registered as an outpatient. He then goes to the prepayment desk to validate his place on the waiting list. This system generates a vast array of frustrations ${ }^{18} »$. One has to be reminded that the status of general practitioner is a very recent addition to the Chinese health system and that there are little, if none, in level 3 hospitals.

This lack of information does not make it possible for the patient to know with certainty which specialist to consult. His waiting time first to get a ticket and then for the consultation is turned into a bigger burden due to the uncertainty of having made the right choice.

What with waiting lines that can last for various days, consultation times that are shrinking, cost that are going up amidst widespread over-diagnosis and over-prescription, one can understand the frustration of patients. If you add the commonly practiced black market of waiting tickets or "red envelopes" bribes to medical personnel to cut through waiting lines, this is how the situation degenerates into violent acts in some cases ${ }^{19}$.

\section{The low social recognition of medical careers and lack of consideration for the medical staff}

According to a 2011 survey by the Chinese Medical Doctor Association, 78\% of respondents did not want their own children to become doctors. As described earlier in this book (Chapter 4), recruitment of students with high potential is getting increasing difficult for medical schools, except the most prestigious ones ${ }^{20}$.

This is to be put in parallel to the poor satisfaction of medical personnel with their current situation: Xinhua news agency reported that nearly $40 \%$ of medical personnel surveyed at 316 hospitals nationally from December 2012 to July 2013 said they plan to give up their profession because of increased violence in hospitals. ${ }^{21}$

In March 2012, an online survey was carried out by the People's Daily after a physician was savagely murdered by a patient, gaining national coverage and strong condemnation from authorities. This survey was inquiring about the emotion this event was triggering into the respondents. An overwhelming 65\% of them answer "joy", against only 14\% for "anger" and 7\% for "sadness". Given its very disturbing results, the study was quickly withdrawn from the newspaper's website. Among the numerous comments this incidents generated, Xu Xialong, a human resources consultant from Beijing, reckoned these results was echoing the feeling of frustration of patients and that the violence of respondents was turned against the system and not really commenting the tragedy itself ${ }^{22}$.

\footnotetext{
${ }^{18}$ Interview in Beijing, November 2015 (translated from Chinese)

${ }^{19}$ Shun Ching Chan, C. «A market of distrust: unofficial payments for Hospital Care in China », (2015) The 12th Conference of the European Sociological Association (ESA 2015)

${ }^{20} \mathrm{http}: / /$ www.ft.com/cms/s/35a081ae-2653-11e3-8ef6-00144feab7de.html\#axzz3dqYRbv78 accessed September 2017

${ }^{21}$ Ibid. Note 26.

22 http://www.bloombergview.com/articles/2012-03-29/violent-crimes-in-china-s-hospitals-spread-happiness accessed September 2017
} 
On a lighter note, in November 2015, an article from the Chinese Medical News praised the training of nurses by flight attendants to adopt a more outgoing and customer-friendly attitude and improve their currently negative image with the public ${ }^{23}$.

In summary, all these anecdotes point out to a lack of respect towards the medical staff. Chicken or egg, it fuels the vicious circle of violence, as trust and respect are absolutely mandatory

\section{The lack of legal recourse in case of suspected medical malpractice}

According to many press articles and academic research, the problem of violence is also tied to an incomplete legal mechanism for patient to address issues during their medical process.

Indeed, China's judicial system was widely improved since the economic reforms. Until the early 80 's, there was no laws or legislation to deal with medical liability or medical malpractice. ${ }^{24}$ In 1985, the municipal government of Shanghai and the provincial government of Shanxi established an experimental form of "administrative" system for handling civil liability in medical malpractice claims in their local administrative regulations.

These experiments provided an administrative institutional path for addressing medical complaints. In 1987, the Ministry of Health drafted the Medical Accident Rules that were promulgated by the State Council. For "harm" caused by a direct medical accident, a patient or patient's family/relatives can seek redress. The term "harm" refereed to death, disfigurement, disability, or serious dysfunction. The burden of proof was upon the plaintiff to prove causation.

The law further subdivides "medical accident" into "technical accidents" (negligent treatment) and "malpractice accidents" (breach of duty, violation of rules or regulations) with the latter having more serious punishments. ${ }^{25}$ This law was highly criticized to be too restrictive. ${ }^{26}$ In response to criticism of the 1987 Rules, the State Council promulgated in 2002 the Medical Accident Regulations. This law broadened the scope of liability for medical practitioners. Hospitals had a greater obligation, at least on paper, to maintain good medical records. The burden of proof remained on patients.

Rapidly after 1987, civil malpractice suits became more common than criminal. A 2011 Chinese Hospital Management Association survey reported that the number of malpractice lawsuits in China has been increasing at an average rate of $23 \%$ a year since $2002^{27}$.

Improving the rights of patient to seek redress, the 2009 Tort Liability Law came into effect in 2010. One of the important changes is that it was an increased attention to the "standard of care $^{28,}$. This law also made clear that medical institutions are liable for their staff ${ }^{29}$.

\footnotetext{
${ }^{23}$ http://www.chinesemedicalnews.com/2015/11/medical-news-from-china-7-stories-that.html accessed September 2017

${ }^{24}$ Wang, Zhu, and Ken Oliphant. "Yangge Dance: The Rhythm of Liability for Medical Malpractice in the People's Republic of China." Chicago-Kent Law Revue 87 (2011): 26-30.

${ }^{25}$ Statute on Handling Medical Accidents, Published June 29, 1987. For a translated copy, see: "1987 Rules on Handling Medical Accidents in China," http://www.china.org.cn/english/2002/Jun/35661.htm accessed September 2017

${ }^{26}$ Harris, Dean M., and Chien Chang Wu. "Medical Malpractice in the People's Republic of China: The 2002 Regulation on the Handling of Medical Accidents." The Journal of Law, Medicine \& Ethics 33.3 (2005): 456-477.

${ }^{27}$ Jiang, Jessie. "In Some Chinese Hospitals, Violence Is Out of Control and It's Doctors Who Are at Risk." Time Magazine. 11 Oct 2011.Web. http://www.time.com/time/world/article/0,8599,2096630,00.html accessed September 2017
} 
Even if China's government is improving its judicial system, there are still a lot of grey zones where patients or relatives may have the feeling of the absence of justice. Most laws and legislations are quite recent and some points of confusion still exist. According to Ryan Rossner (2014), "Liability for medical errors took many decades to be formally established in the People's Republic of China, and the use of administrative 'appraisal panels' and mediation reflect a continued preference for reducing litigation and limiting compensation for medical liability."

\section{Changes in demand}

\section{Spatial changes in healthcare demand}

\section{... Including urbanization}

With the improvement of the transport and communication network, people have become more mobile, including in rural areas. They don't hesitate any more to travel long distances to be treated in major hospitals in cities, even sometimes out of their home province.

The constraints put by public insurance to get reimbursement do not seem to give enough incentive to curb the phenomenon. As explained in the chapter on health insurance (Chapter 6), the 3 main public insurance schemes cover a remarkable share of the population, but the level of coverage remain quite limited, especially for outpatient consultations. Out of pocket payments are high for the patient who has to arbitrate between:

1. Consult in a hospital with high quality standards, with little or no reimbursement

2. Go to a local health center getting better but still limited coverage

The figures showing the congestion in level 3 hospital tend to show that a major part of the population choose the first option, except those in the direst situation of poverty.

For migrants and commuters, the obligation to go back to their registered place of residence in case of health troubles has been considerably reduced. It is increasingly common for companies to have agreements with hospital for medical consultations for their employees, including migrant workers.

\section{... Occupation changes}

Yet, one factor that cannot be neglected is the importance of having family or a social network close to the place of hospitalization. Indeed, in Chinese hospitals, family and relatives of patients plays a crucial part in the care and healing process. The non-medical services supplied by the hospital, such as catering, are minimal and the family needs to be very present to support the patient:

- For his meals, as glass or cutlery can be missing and food itself is very basic

\footnotetext{
${ }^{28}$ Wang S, Annotations of the Tort Liability Law of the People's Republic of China. China Legal Press, 2010: $274-$ 268.[In Chinese]; Xi and Yang, "Medical Liability Laws," 72.

${ }^{29}$ Article 54, 2009 Tort Liability Law of the P.R.C.

${ }^{30}$ Ryan Rossner's report (2013),

http://chinamedicalboard.org/sites/chinamedicalboard.org/files/rossner30sept13.pdf

accessed September 2017
} 
- But also to get full attention from medical personnel: the presence and monitoring of relatives has an influence on the way the patient is treated, not to mention the "hong bao" or red envelopes filled with money to boost the engagement of the staff for the patient.

The presence of family or social network living close the hospital is thus a key element. EY ${ }^{31}$ a consulting group, surveyed consumers who are employed and whose incomes fall solidly into mainland China's mid-to-upper middle class: annual incomes of RMB 60,000 to 229,000. 79\% of survey respondents indicated that they have to return to the place of their household registration to get health care. Of this group, 49\% would return home for any health problem, and 30\% would return for only serious medical issues.

Studies from Milcent (2015) show that access to healthcare is all the more difficult for rural inhabitants with agricultural activity compared to rural inhabitants ${ }^{32}$. When people commute on a regular basis to cities, travelling long distances to go to a level III hospital is not that much of a hurdle. In addition, they are more likely to have some kind of network in cities. As the share of really sedentary population in rural areas is shrinking, this explains why this factor cannot prevent the congestion of the best hospital in cities, partially due to the inflow of patients from other areas.

\section{The dissemination of the information: Internet and web platforms}

\section{For the public}

The internet plays also an important part in the appeal of big public hospitals, acting as a sounding board to disseminate information. It makes it possible pour individuals to have private or semi-private discussion forums, or at least appearing so, in which speech and criticism can be more direct. It is very common for families to use such forums to protest against the quality of care. Oppositely, the list of elite healthcare institution published by Shanghai's Fudan University was singled out by many microbloggers, who have disseminated the information that belonging to this list was a certain label of quality.

\section{According to Wei Zhong, Professor at Chinese Academy of Social Sciences (CASS) :}

"Ten years ago, there already were conflicts between patients and medical personnel, sometimes involving violence. Cases of medical malpractice leading to anger and frustration on the patient side were already out there. Yet, they were gaining seldom coverage on printed newspapers. There was the case of the coffin of a deceased child that the family had placed at the entrance of the hospital, which was widely commented across China and considered quite unique, even though it wasn't. Today, it is possible to find all kinds of similar stories every day all across the internet. Families living thousands of kilometers apart can share their pain and frustration with the healthcare system. This undoubtedly fuels violence. »

\footnotetext{
${ }^{31} \mathrm{EY}$, the rise of private health insurance in China | Consumer demand presents huge opportunities and risks 2016.

http://www.ey.com/Publication/vwLUAssets/EY-the-rise-of-private-health-insurance-in-china/\$FILE/EY-therise-of-private-health-insurance-in-china.pdf accessed September 2017

32 Milcent, C. (2015) "Industrialization and inequalities: healthcare in Chinese rural areas*”, C. Milcent, under revision for Revue Economique.
} 
Hospitals sometimes try to disconnect the physician from the aftermath of cares that do not turn out as expected. For instance, the patient can be transferred to another hospital, with the family being notified only afterwards. In such cases, they cannot materially « seek justice» (tao gongdao), they can digitally post their complaints and criticism. It is possible that sharing these types of experience reduce the sense of powerlessness vis-à-vis the asymmetry of information between the family and medical personnel. Internet enables patients and their relatives to understand better their rights ${ }^{33}$, it corrects the asymmetry of information and elevates the level of expectations in terms of quality of care.

\section{For the authorities}

For China's Ministry of Public Security, the use of microblogs is also a tool to interact with the public. It can be a way to release «correct and authorized information to dispel misunderstandings, and serve the people» as explained by Huang Ming, the vice minister of Public security ${ }^{34}$.

\section{The medical literacy level of patients and their relatives}

As exposed by Zhong Nanshan in his speech at the China's National People's Congress in March 2014, violence against health-workers can be explained by low medical literacy among the public.

Some reckon that, due to their lack of education, patients could fail to understand the difficulty or impossibility to treat certain pathologies, explaining in the end the violence ${ }^{35}$. Yet, literacy level and superstitions are quite comparable to what can be found in neighboring countries, even though they don't have to face the same violence phenomenon. Thus, it doesn't appear to actually be a key criteria.

\section{How to restore trust, respect and understanding between patients and medical staff? In a nutshell, decentralize the quality care offer}

\section{Improvement in physician qualification and mobility}

The training of physician in China is both complex and very diverse depending on each geographical area. Yet, it is overall insufficient. In 2013, only $28.5 \%$ of the healthcare in hospital was provided by personnel with Bachelor's degree of above. This figure is on the increase, since

\footnotetext{
${ }^{33}$ New Law combats the « yinao » phenomenon, December 2015, What's on weibo. http://www.whatsonweibo.com/new-law-combats-chinas-yinao-phenomenon/ accessed September 2017

34 http://www.chinadaily.com.cn/china/2011-09/27/content_13796619.htm accessed September 2017

35 They are often referred to as «ignorant people» on forum and social networks such as Sina weibo.
} 
it was only $26.7 \%$ the previous year ${ }^{36}$. In rural areas, situation is even worse with $70 \%$ of medical personnel having only junior high school training ${ }^{37,38}$.

The low professional mobility of doctors: In theory, a physician having graduated as a "rural doctor » will not be able to consult in urban areas, even though seniority can make up for the diploma in certain cases.

Within each area, mobility is also low. The professional registration number of each doctors is attached to the hospitals he works for. Globally speaking, he cannot work elsewhere, even part time, even though some pilot experiments are currently tested. As a consequence, recruitment of highly qualified doctors is extremely difficult for a private hospital, as most graduates from renowned medical universities will chose to work in a level 3 hospital.

As there is a strong correlation between highly trained medical personnel and level 3 hospitals, competition on each geographical area is limited: only such hospitals are really attractive for patients, thanks to the training and skills of their staff.

More details are provided Chapter 4, on the medical staff and its incentives.

\section{Police presence as short term fix}

As a first answer to this phenomenon, the government reacted by increasing the security in hospitals.

The attack described earlier, against a physician in Guangdong, lead to this security response. The Health and Family Planning Commission requested the implementation of a police antenna in each hospital with regular patrols for swift intervention in case of incident. Surveillance cameras and alarms were also installed.

At national level, , the Ministry of Public Security (MoPS) advised in October 2013 hospitals with 2000 beds to have at least 100 security guards. The Vice Minister of Public Security Huang Ming said at the end of March 2016 that « Chinese police would crack down on hospital-related crimes and show zero tolerance to perpetrators who assault and injure medical personnel $\gg .{ }^{39}$

This answer to violence through increased security can only be a short term fix. They contribute to the mistrust towards the healthcare system and cannot really improve the situation as long as the root causes are not addressed.

\footnotetext{
${ }^{36}$ That year, the number of registered doctors was reaching 2.06 for 1000 inhabitants, the number of nurses was 2.05 and the number of beds 4.55 .

37 初級中學

${ }^{38}$ Eggleston K., Li L., Qingyue M., Lindelow M., Wagstaff A. (2008) « Health Service Delivery in China : a literature Review ", Health Economics, Vol 9, No.2

${ }^{39}$ http://english.sina.com/news/2016-05-07/doc-ifxryahs0466505.shtml accessed September 2017
} 


\section{In the mid-term, family doctors are seen as the way to re-build trust}

In China, it is not yet common for physicians to enter in a dialogue with the patients, to explain the diagnosis and discuss treatment. Patient/doctor communication plays a very small part in the consultation. In a recent conference, Bo Tang ${ }^{40}$ Secretary General, Physician Commission of District Healthcare, compared consultations held in Hong Kong versus those in mainland China. He pinpointed this lack of dialogue as one of the main differences, contributing to the poor relation between patients and doctors.

To solve this situation, one of the objectives of the reform introducing CHCs was to enable a long term relationship between patients and their doctor. All CHCs are supposed to have a pool of general practitioners who would be able follow their patients on the long run. Close both geographically and in terms of relationship, they could restore trust.

Actually, what is often used as a benchmark is the relationship that could exist between «barefoot doctors » and their patients, in spite of their very light training. The characteristics of this relationship were

- Proximity, that was making it possible to avoid misunderstandings

- The absence of pecuniary factors, made possible by the financing

- The consultation time, that had little constraint.

To re-build this type of relationship, pilot experiment are carried out, setting up family doctors whose revenue is totally disconnected from volume of consultation and prescription ${ }^{41}$.

Yet, it can only be a mid-term solution on a large, since it requires a large cohort of general practitioners that today does not exist, since specific training for GP is fairly new (See Chapter 4).

\section{Insurance schemes as a tool to streamline demand}

The implementation of public insurance schemes is an opportunity to re-create a patient trajectory and ease the congestion of public hospitals, by conditioning reimbursement to the place where the consultations happens. Yet, public insurance coverage of medical consultations remains low and the basket of care covered is limited ${ }^{42}$. In reality, this gives little financial incentive to patients, who still opt for the quality of care versus its geographical or financial accessibility. This is one of the main reasons why dispensaries, primary care centers and level 1 hospital have so far failed to fully find their place.

To solve this, better coverage of consultations in CHCs and township centers is seen as one of the potential solutions to stream some demand out of public hospitals. With a real incentive to make the first of the patient trajectory in less congested establishments, a real patient trajectory could be re-created, improving the efficiency of the overall system. Yet, on top of the financial incentive, a strong policy to improve the training of physicians and quality of these establishments needs to be carried on to really shift the demand out of public hospitals.

\footnotetext{
${ }^{40}$ Bo Tang, Secretary General, Physician Commission of District HealthCare) during his presentation « how doctors establish new rules and consensus in the internet era » during the conference «New Era of internet+ Health : Value Discovery and Ecological Restructuring » held by CASS on November $21^{\text {st }} 2015$ in Beijing.

${ }^{41}$ This point was already described in the chapter on hospital personnel.

${ }^{42}$ Milcent C. et B. Wu « How Do You Feel? The Effect of the New Cooperative Medical Scheme in China", (2015) Journal of Development Studies, Volume 51(12): 1585-1602.
} 
In parallel, the implementation of private insurance is encouraged. They often include private health structures. This integrated system is was is called Managed Care in the USA. So far, the lack of mobility of medical personnel has been an obstacle to the development of such schemes, as well as remaining administrative hurdles that make this type of investment quite complicated for investors.

\section{Internet as a tool for healthcare efficiency}

Digital tools can also play a role to address the issue of concentration of demand. As will be shown in a later chapter, it enables a better efficiency of the system, by supporting the new policies, such as the implementation of family doctors.

One of the potential benefits of internet tools is to solve the issue of incredibly long waiting lines in hospital entrance halls. Patients can make appointments and pay online to avoid physically queuing. In Beijing, it is now mandatory to use such tools, even though an alternative phone number has been put in place for the elderly to make appointment.

Internet and mobile apps thus appear as an instrument to regulate demand and reduce the congestion in level 3 hospitals. Yet, if they make it possible to reduce the standing time, it cannot reduce the total lead time to actually get a consultation. In the end, patients wait at home instead of waiting in the hospital. This already had some benefits, as it makes it possible for medical personnel to work in a much less tense environment, with the pressure of other patients actually waiting. It also eliminates to a large extent the black market of waiting tickets.

Internet can also to offer innovative tools for the medical practice itself, such as telemedicine and teleconsultation. If at least part of the demand currently turning to public hospitals could be redirected to online consultations, it would ease the congestion phenomenon, eventually leading to reduced waiting times and longer consultation times, restoring dialogue and trust between patients and medical personnel. Why do people trust the online consultation services? This virtual consultation is provided by qualified and trained doctor working in high-tech hospitals. A grey zone in the Chinese legislation makes it possible for a physician to offer online consulting services.

It also introduces a form of competition between normal consultations and online consultations, potentially curbing the trend of increasing prices for patients. Yet, solutions brought about by digital tools are not without drawbacks. On the flip side, they raise issues such as the confidentiality of medical data, the responsibility in terms of medical malpractice or the control of quality standards that are offered. 
Prof. Carine MILCENT

Carine.milcent@psemail.eu

CNRS - PSE

Tu J. "Yinao : Protest and Violence in China's Medical Sector», dec.2015, Berkeley Journal of Sociology. http://berkeleyjournal.org/2014/12/yinao-protest-and-violence-in-chinas-medicalsector/

accessed September 2017

Wang, Zhongming and Jianhua Li. 2012. "Yiliaojiufen fasheng de yuanyin ji yingduicuoshi”" ("The reason and countering measures of medical disputes"). Zhongguo Shequ Yishi (Chinese Community Doctor). No. 12, 409-410.

Cao, Kai. "Hospitals' Return to Public Service Key to Tackle Doctor-Patient Disputes.” Xinhua 19 Nov 2011. Web. 30 Sep. 2013.

Tucker JD, Cheng Y, Wong B, et al. Patient-physician mistrust and violence against physicians in Guangdong Province, China: a qualitative study. BMJ Open. 2015;5(10)

Urban China: Toward Efficient, Inclusive, and Sustainable Urbanization Par The World Bank;Development Research Center of the State Council, Source MoH, 2011.

Barber S., Borowitz M., Bekedam H et Ma J. (2014) «The hospital of the future in China: China's reform of public hospitals and trends from industrialized countries » Health Policy and Planning, 29(3):367-78

Lim M., Yang T., Zhang Z., Zhao F., Feng, W., Chen, Y. (2002) «The role and scope of Private Medical Practice in China» Final report to the world Health Organization and the United Nations Development Program, UNDP, WHO and MOH China.

Shun Ching Chan, C. «A market of distrust: unofficial payments for Hospital Care in China », (2015) The 12th Conference of the European Sociological Association (ESA 2015)

Wang, Zhu, and Ken Oliphant. "Yangge Dance: The Rhythm of Liability for Medical Malpractice in the People's Republic of China." Chicago-Kent Law Revue 87 (2011): 26-30.

Harris, Dean M., and Chien Chang Wu. "Medical Malpractice in the People's Republic of China: The 2002 Regulation on the Handling of Medical Accidents." The Journal of Law, Medicine \& Ethics 33.3 (2005): 456-477.

Jiang, Jessie. "In Some Chinese Hospitals, Violence Is Out of Control and It's Doctors Who Are at Risk." Time Magazine. 11 Oct 2011.Web. http://www.time.com/time/world/article/0,8599,2096630,00.html accessed September 2017

Wang S, Annotations of the Tort Liability Law of the People's Republic of China. China Legal Press, 2010: 274268. [n Chinese]; Xi and Yang, "Medical Liability Laws," 72.

EY, the rise of private health insurance in China | Consumer demand presents huge opportunities and risks 2016. http://www.ey.com/Publication/vwLUAssets/EY-the-rise-of-private-health-insurance-in-china/\$FILE/EY-therise-of-private-health-insurance-in-china.pdf accessed September 2017

Milcent, C. (2015) “Industrialization and inequalities: healthcare in Chinese rural areas", under revision for Revue Economique.

Eggleston K., Li L., Qingyue M., Lindelow M., Wagstaff A. (2008) «Health Service Delivery in China : a literature Review », Health Economics, Vol 9, No.2 
Prof. Carine MILCENT

Carine.milcent@psemail.eu

CNRS - PSE

Bo Tang , Secretary General, Physician Commission of District HealthCare) during his presentation "how doctors establish new rules and consensus in the internet era » during the conference « New Era of internet+ Health : Value Discovery and Ecological Restructuring » held by CASS on November $21^{\text {st }} 2015$ in Beijing.

Milcent C. et B. Wu «How Do You Feel? The Effect of the New Cooperative Medical Scheme in China", (2015) Journal of Development Studies, Volume 51(12): 1585-1602. 